\title{
Strategi Personal Branding Selebgram Non Selebriti
}

\author{
Christhoper Rafael Butar Butar ${ }^{1}$ dan Dini Salmiyah Fithrah Ali² \\ ${ }^{1,2}$ Universitas Telkom
}

\begin{abstract}
ABSTRAK
Media sosial Instagram saat ini telah menjadi media alternatif dalam bidang pemasaran maupun promosi. Secara personal, pribadi dapat melakukan bisnis melalui Instagram. Saat ini, selebgram sedang menjadi tren di kalangan pengguna Instagram di Indonesia. Menjadi seorang selebgram harus memiliki keunikan tersendiri untuk dapat berbeda dengan selebgram kompetitor lainnya. Dalam membangunnya, dibutuhkan personal branding yang baik untuk dapat bertahan dalam dunia selebgram di Instagram. Ohim dengan akun@ ibrhmrsyd tanpa adanya latar belakang sebagai selebriti turut memperoleh gelar selebgram. Personal branding yang dilakukan Ohim menarik perhatian produk-produk ternama dengan hanya menggunakan Instagram sebagai alat penyampaian pesan komunikasinya. Dirinya dapat dilirik dan menarik perhatian brand ternama di Indonesia dan menjadikannya seorang endorser dalam selebgram. Dirinya menjadi salah satu selebgram di Kota Bandung yang mewakili produk ternama tersebut. Penelitian ini membahas tentang bagaimana strategi personal branding selebgram non selebriti. Metode yang digunakan adalah deskriptif kualitatif dengan indikator terdiri dari kesebelas karakteristik authentic personal branding oleh Rampersad. Hasil penelitian menyebutkan bahwa strategi personal branding Ohim ialah memiliki nilai, karakter, kode perilaku dan moral, berfokus pada satu bidang, konsisten, memiliki relevansi, memiliki visibilitas, mendapatkan pengakuan, menerapkan hal positif, serta menjadi diri sendiri dengan tetap menjaga eksistensinya dan selalu memelihara hubungan yang terjalin baik dalam akun Instagram @ibrhmrsyd maupun kesehariannya.
\end{abstract}

Kata-kata Kunci: Personal branding; media sosial; instagram; selebgram; strategi

\section{Personal Branding Strategy Of Celebgram Non Celebrity}

\begin{abstract}
Social media like Instagram nowadays has become an alternative media in marketing and promotions. Personally, people can do business through Instagram.Nowadays, Selebgram is becoming a trend among Instagram users in Indonesia.Being a celebgram should have their own uniqueness to be different from the others. In building it, it takes a good personal branding in order to survive in celebgram world inside the Instagram. Ohim with his account @ibrhmrsyd without a celebrity background has earned celebgram title. The personal branding that Ohim done attracting some brands with just using Instagram as the tools of delivering communication messages. He can be glimpsed and attracting some well-known brand in Indonesia and chosen as the selebgram endorser. Ohim become one of celebgram in Bandung city that chosen to representing some famous products. This study discusses how personal branding strategy of celebgram noncelebrity. This study using descriptive qualitative method with the indicators consist of eleven characteristics of authentic personal branding by Rampersad. The result says that Ohim 's personal branding strategies has value, character, code of behavior and moral, focusing on selected area, consistency, relevance, visibility, gain rcognitions, applying the positive things, and be yourself while maintaining his existences in become celebgram and also always maintain the relationship in both inside@ibrhmrsyd s Instagram account and daily life.
\end{abstract}

Keywords: Personal branding; social media; instagram; celebgram; strategy

Korespondensi: Christhoper Rafael Butar Butar, S.Ikom. Program Studi Ilmu Komunikasi, Fakultas Komunikasi dan Bisnis, Universitas Telkom, Jl. Telekomunikasi Terusan Buah Batu, Bandung 40257. Email: christhoperbb@gmail.com 


\section{PENDAHULUAN}

Pengguna media sosial saat ini sangatlah banyak, hampir semua kalangan menggunakan media sosial. Penggunaan media sosial berbasis Internet yang sedang terkenal di kalangan remaja saat ini ialah Instagram. Menurut statistik yang diperoleh dari We Are Social's, pada awal Januari 2016, persentase pengguna Instagram di Indonesia mencapai angka 10\% dari total jumlah penduduk.

Banyak bisnis yang telah berkembang melalui aplikasi Instagram. Instagram dijadikan sebagai media dalam mempromosikan maupun menjual produk. Kini, bukan hanya perusahaan yang memiliki akun Instagram saja yang dapat melakukan pemasaran.

Secara personal, pengguna aplikasi Instagram pun dapat melakukan bisnis dengan turut melakukan pemasaran melalui akun Instagram pribadinya. Melalui share foto, dan memiliki fitur followers, Instagram telah memudahkan konsumen untuk melihat produk yang dijual dan dapat langsung memberi komentar di bawah foto yang diminati.

Selebgram merupakan salah satu alat promosi berbasis new media guna meningkatkan citra dan identifikasi suatu produk atau jasa.Saat ini, aktivitas komunikasi dan bertukar informasi pada dunia maya sangatlah deras arusnya.

Setiap orang berlomba-lomba untuk membangun personal branding-nya sesuai dengan bidang keahlian dan ketertarikan yang dimiliki. Banyak artis yang kemudian memanfaatkan media massa untuk berbagai tujuan seperti menaikkan reputasi, membuat sensasi agar namanya tetap populer, atau memanfaatkan media sebagai media promosi untuk kepentingan bisnisnya, dan lain-lain (Pattipeilohy, 2015). Tak terkecuali pada mereka yang disebut selebriti dalam Instagram atau biasa dikenal dengan istilah selebgram.

Selebriti Instagram semakin hari semakin banyak yang bermunculan, dengan masingmasing pribadi memiliki keunikan karakter dan gaya yang berbeda guna menunjang citra yang ada pada akun Instagramnya. Menjadi seorang selebriti Instagram, harus memiliki keunikan tersendiri untuk dapat berbeda dengan selebgram yang lainnya. Dalam membangun keunikan tersendiri, membangunnya melalui personal branding yang baik adalah hal utama yang dapat menciptakan keunikan pribadi bagi selebgram.

Personal branding adalah suatu citra atau pemikiran yang muncul pada benak pikiran orang terhadap suatu hal yang dilihat atau 
didengar. Ibrahim Risyad Z. W. dengan akun Instagramnya yaitu@ibrhmrsyd atau biasa dikenal dengan panggilan Ohim adalah salah satu selebgram dengan berlatar belakang non selebriti. Dengan akun Instagram Ohim sebagai sarana penyampaian pesan dan komunikasi, Ohim mempresentasikan dirinya menjadi pribadi yang memiliki ketertarikan akanfashion.

Ketertarikannya terhadap fashion terlihat dari akun Instagram yang dimiliki oleh Ohim dalam feed-nya. Terlihat bahwa akun @ ibrhmrsyd mengunggah foto yang kebanyakan mengenakan pakaian yang casual dan lebih menonjolkan foto ke arah pakaian yang dikenakannya.

Ohim berprofesi sebagai mahasiswa di salah satu universitas swasta ternama di Bandung. Tanpa adanya latar belakang sebagai selebriti, Ohim dapat dilirik dan menarik perhatian brand ternama di Indonesia seperti: Uniqlo Indonesia dan Go-BOX Indonesia serta turut dijadikan endorser dari perusahaan yang bekerja sama dengan dirinya.

Lebih lanjut, Ohim adalah salah satu dari dua selebgram di Kota Bandung yang digunakan oleh perusahaan GO-JEK Indonesia untuk merepresentasikan produk GO-BOX dan GO-PAY yang dimiliki oleh perusahaan GO-JEK Indonesia, serta Ohim menjadi salah satu selebgram di Kota Bandung yang dipilih oleh UNIQLO, yaitu sebuah perusahaan yang bergerak di bidang pakaian dan fashion untuk merepresentasikan produk UNIQLO kepada khalayak, baik dalam keseharian maupun dalam media Instagram.

Personal branding sekilas yang tampak pada akun Instagram @ibrhmrsyd adalah pribadi Ohim yang mencintai fashion, travelling dan fotografi. Hal ini terlihat bagaimana komposisi foto yang diunggah ke dalam akun @ibrhmrsyd memiliki banyak style dan lebih mencondongkan foto yang berisi dengan tampilan fashion yang dikenakan oleh Ohim sebagai pemilik akun Instagram @ibrhmrsyd. Namun, personal branding yang terbangun padanya lebih terarah ke dalam bidang fashion.

Jika dilihat dengan sekilas, kebanyakan dari kita kurang begitu mengenal dan mengetahui selebgram tersebut yang telah berhasil mengait brand ternama hanya dengan tampilan personal branding yang dimiliki dalam akun Instagramnya. Strategi citra, merek atau personal branding yang diterapkan oleh Ohim melalui media komunikasi, yaitu akun Instagramnya menimbulkan antusias yang tinggi pada penulis untuk mengetahui unsur apa saja yang dimiliki Ohim yang disusun dan diterapkan dalam merepresentasikan dirinya terkait citra yang dimiliki melalui akun Instagramnya.

Berdasarkan uraian latar belakang di atas, maka rumusan masalah pada penelitian 
ini adalah: Bagaimana penerapan personal branding dalam akun Instagram @ibrhmrsyd?. Teori utama yang digunakan peneliti dalam penelitian ini adalah teori personal branding yang berisikan sebelas karakteristik personal branding, sebagai berikut: (1). Authenticity (keaslian), (2). Integrity (integritas), (3). Consistency (konsisten), (4). Specialization (spesialisasi), (5). Authority (wibawa), (6). Distinctiveness (kekhasan), (7). Relevant (relevan), (8). Visibility (visibilitas), (9). Persistence (kegigihan), (10). Goodwill (kebaikan), (11). Performance (kinerja). (Rampersad, 2008).

\section{METODE PENELITIAN}

Dalam penelitian ini, penulis melakukan wawancara langsung terhadap informan kunci daripenelitian iniserta turutmelakukanobservasi terhadap dokumentasi yang dimiliki dan melakukan tinjauan literatur untuk mendukung hasil penelitian. Metode yang digunakan dalam penelitian ini adalah deskriptif kualitatif. (Rakhmat, 2009) menyatakan bahwa penelitian deskriptif ditujukan untuk: (1). mengumpulkan informasi aktual secara rinci yang melukiskan gejala yang ada, (2). mengidentifikasi masalah atau memeriksa kondisi dan praktik-praktik yang berlaku, (3). membuat perbandingan atau evaluasi, (4). menentukan apa yang dilakukan orang lain dalam menghadapi masalah yang sama dan belajar dari pengalaman mereka untuk menetapkan rencana dan keputusan pada waktu yang akan datang. Penelitian kualitatif adalah penelitian yang bermaksud untuk memahami fenomena tentang apa yang dialami oleh subjek penelitian (Moleong, 2012).

Menurut Setianti, dkk. (2016) pendekatan kualitatif sebagai prosedur penelitian yang menghasilkan data deskriptif berupa kata-kata tertulis ataupun lisan dari orang-orang dan perilaku yang dapat diamati. Penelitian yang diangkat oleh penulis bersifat sosial sehingga penulis memilih metode deskriptif kualitatif dengan tujuan untuk meneliti objek secara mendalam dan untuk lebih dapat memahami tentang hal-hal yang berkaitan dengan latar belakang subjek penelitian. Adapun unit analisis pada penelitian ini dirangkum dalam tabel 1 .

\section{HASIL DAN PEMBAHASAN}

Sesuai dengan tujuan penelitian yang mengarah pada mengetahui bagaimana penerapan strategi personal branding dalam akun Instagram @ibrhmrsyd serta menganalisanya, strategi personal branding selebgram non selebriti ini didahului dengan pemenuhan terhadap kriteria personal brand yang dibutuhkan seseorang untuk dapat melakukan personal branding. Kriteria yang 
Tabel 1 Unit Analisis

\begin{tabular}{|c|c|c|}
\hline Variabel & Sub Variabel & Indikator \\
\hline & 1. Authenticity (Keaslian) & Dibangun atas kepribadian sejati dalam \\
\hline & & diri dan mencerminkan karakter, nilai- \\
\hline & & nilai, dan visi yang dimiliki pribadi. \\
\hline & 2. Intergrity (Integritas) & Kode moral dan perilaku dalam personal \\
\hline & & branding. \\
\hline & 3. Consistency (Konsisten) & Kekonsistenan pesan dan perilaku dalam \\
\hline & & personal branding. \\
\hline & 4. Specialization (Spesialisasi) & Fokus terhadap satu bidang bakat atau \\
\hline & & keterampilan. \\
\hline & 5. Authority (Wibawa) & Diakui dalam bidang tertentu, \\
\hline & & berpengalaman, dan sebagai pemimpin \\
\hline \multirow{13}{*}{ Personal branding } & & yang efektif \\
\hline & 6. Distinctiveness (Kekhasan) & Bedakan diri berdasarkan merek, unik dan \\
\hline & & berbeda dari kompetisi. \\
\hline & 7. Relevant (Relevan) & Personal branding berhubungan dengan \\
\hline & & khalayak dan dianggap penting. \\
\hline & 8. Visibility (Visibilitas) & Personal branding disiarkan berkali-kali, \\
\hline & & terus menerus, konsisten dan berulang \\
\hline & & kali. \\
\hline & 9. Persistence (Kegigihan) & Harus konsisten pada personal branding \\
\hline & & yg dibentuk, membutuhkan dedikasi, \\
\hline & 10. Goodwill (Kebaikan) & $\begin{array}{l}\text { pengorbanan, perencanaan dan kesabaran. } \\
\text { Hubungan baik, pengakuan positif dan }\end{array}$ \\
\hline & & bermanfaat. \\
\hline & 11. Performance (Kinerja) & Perbaikan diri akan personal branding. \\
\hline
\end{tabular}

Sumber: Hasil Penelitian, 2016

digunakan oleh penulis dalam penelitian ini adalah kriteria yang dikemukakan oleh Montoya dan Rampersad (2008).

Dalam membangun personal branding melalui media Instagram sebagai seorang selebgram, selebgram menggunakan fitur visual yang diunggulkan Instagram dalam menyampaikan pesan personal branding yang dibentuk. Konten-konten yang diunggah ke dalam akun Instagram pun haruslah memiliki 
Tabel 2 Rangkuman Hasil Wawancara

\begin{tabular}{|c|c|c|}
\hline \multirow{3}{*}{ No. } & \multirow{3}{*}{ Variabel } & Hasil Wawancara \\
\hline & & Ibrahim Risyad Z.W \\
\hline & & (@ibrhmrsyd) \\
\hline \multirow[t]{2}{*}{1.} & Authenticity & Seorang selebgram yang berprestasi, simple dengan style yang casual \\
\hline & (Keaslian) & dan ga ribet. \\
\hline \multirow[t]{2}{*}{2.} & Intergrity & Selalu mengunggah dan memberikan hal-hal positif dan lebih teratur \\
\hline & (Integritas) & dan simple feed Instagram agar enak dilihat orang. \\
\hline \multirow[t]{2}{*}{3.} & Consistency & Konten yang tertata serta menjunjung tinggi etika dalam konteks pesan \\
\hline & (Konsisten) & yang akan diunggah. \\
\hline
\end{tabular}
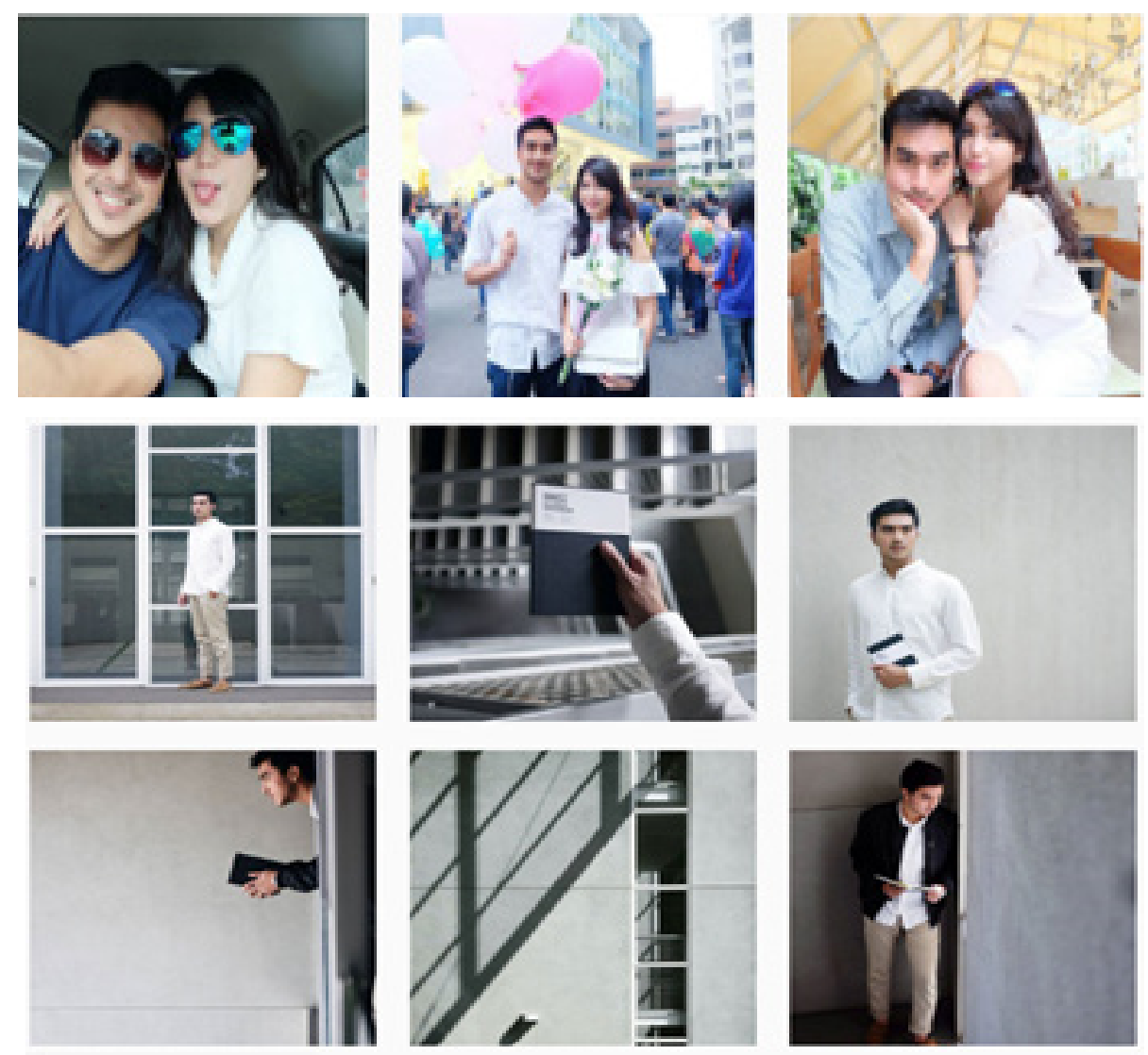

4. Specialization

Lebih ke talent sama model fashion men. Menspesifikan khususnya di (Spesialisasi) men model, casual men model di bidang fashion.
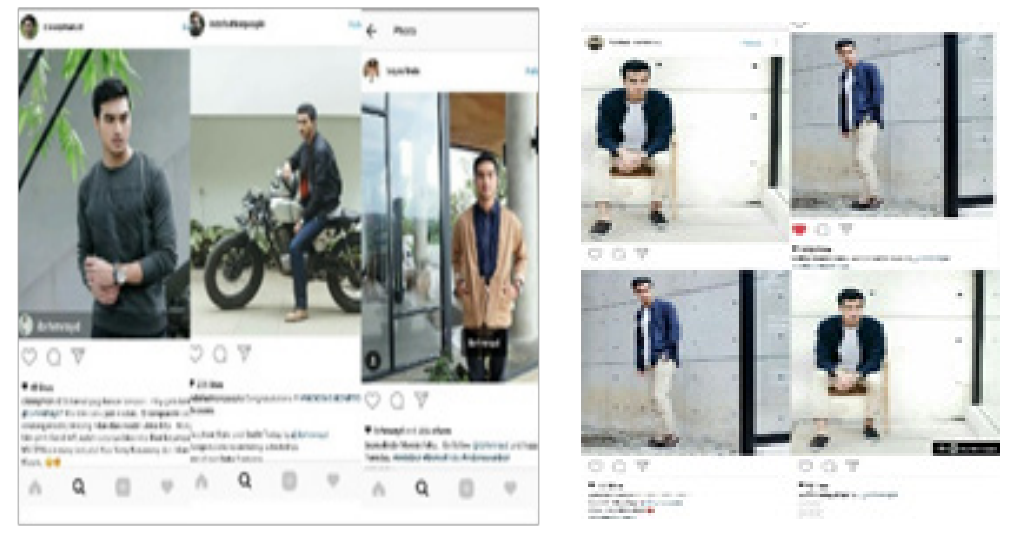
5. Authority (Wibawa)

6. Distinctiveness

(Kekhasan)

7. Relevant

(Relevan)

8. Visibility

(Visibilitas)

9. Persistence

(Kegigihan)

10. Goodwill

(Kebaikan)

11. Performance
Pengalaman yang dimiliki turut diakui oleh klien serta akun-akun Instagram yang mengunggah kembali foto dirinya.

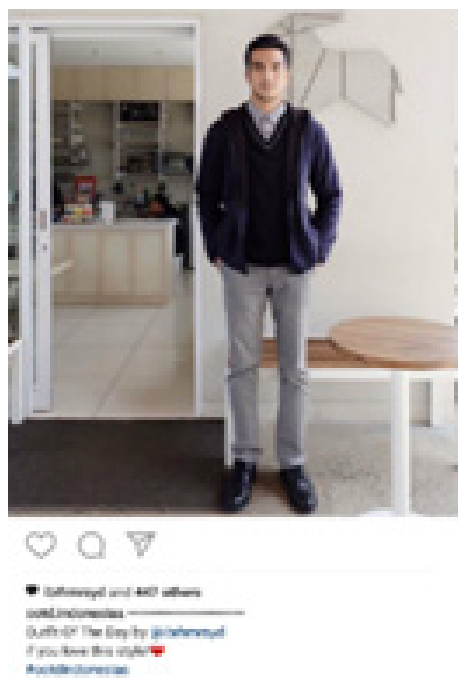

Sebagai selebgram berprestasi (memiliki prestasi dalam bidang yang ditekuni oleh dirinya). Memiliki relationship goals. Beberapa sutradara, sutradara iklan, fashion blogger, koreografer, dan pengamat-pengamat fashion mulai menjadi followers dalam akunnya. Selalu menggunggah foto kegiatan dirinya, prestasi dirinya dalam fashion, dan mengikuti kekonsistenan yang diterapkan. Adanya pengakuan selebgram atas dirinya yang diakui oleh media dan tetap mengikuti yang telah ditetapkan dirinya untuk tidak lari dari alur yang telah ditetapkan.

Hasil yang baik dalam bekerja, kepuasan untuk klien-klien yang bekerja sama dengan dirinya.

Tetap sesuai dengan track yang ditetapkan Ohim.

(Kinerja)

keselarasan dengan ambisi pribadi yang dimiliki.

Dalam membangun personal branding melalui media Instagram sebagai seorang selebgram, selebgram menggunakan fitur visual yang diunggulkan Instagram dalam menyampaikan pesan personal branding yang dibentuk. Konten-konten yang diunggah ke dalam akun Instagram pun haruslah memiliki keselarasan dengan ambisi pribadi yang dimiliki. Menurut Nugraha, dkk (2017) pada dasarnya penetapan branding dapat memberikan kelebihan branding suatu produk dan jasa.

Nilai yang dibentuk oleh Ohim dalam 
menjadi seorang selebgram adalah sebagai seorang selebgram yang mempunyai prestasi yang tidak hanya mencondongkan foto-foto dirinya ataupun memamerkan sisi terbaik dirinya. Prestasi yang dimaksudkan oleh Ohim adalah prestasi dimana konten yang dimilikinya memiliki kegiatan yang merepresentasikan bagaimana prestasi dirinya dalam pekerjaan yang ditekuninya.

Karakter yang dibentuk Ohim membentuk personal branding dirinya sebagai seorang selebgram yang simple, tidak memiliki sifat yang rumit dan terkesan santai. Hal ini sesuai dengan konten yang diunggahnya ke dalam akun@ibrhmrsyd yang lebih mengutamakan sisi casual pada setiap kontennya. Ambisi pribadi yang Ohim terapkan pun memiliki keselarasan dengan karakter yang dibentuk, karena keseharian yang dijalaninya sesuai dengan karakter yang diaplikasikannya.

Berdasarkan karakteristik yang terdapat dalam Rampersad (2008), penulis dapat menyimpulkan bahwa Ohim telah memenuhi beberapa poin dalam authenticity (keaslian). Namun, memiliki kekurangan dalam sisi visi, bahwa Ohim sebagai seorang selebgram tidak memiliki visi yang ditetapkan dalam menjadi seorang selebgram di media Instagram.

Intergritas dalam Rampersad (2008) adalah mematuhi kode moral dan perilaku yang ditetapkan oleh ambisi pribadi. Dalam membentuk dan membangun personal branding yang otentik, taat kepada kode moral dan perilaku yang telah ditetapkan oleh ambisi pribadi adalah kunci utama dalam menciptakan personal branding yang dapat dipandang baik oleh khalayak.

Perilaku dan moral yang telah dibentuk oleh Ohim sebagai seorang yang simple, Ohim mengemas konten Instagramnya menjadi simple dan teratur dengan tetap memperhatikan komposisi konten yang tidak mencerminkan pribadi yang negatif, dan selalu melakukan penyaringan terhadap konten yang akan diunggah pada akun@ibrhmrsyd agar konten selalu layak di benak khalayak yang dimiliki pada akun Instagram @ibrhmrsyd. Hal ini menurut penulis telah sesuai dengan konsep yang ada, karena dalam membentuk sebuah personal branding yang otentik haruslah didasarkan ada aturan yang telah ditetapkan oleh pribadi, dan integrity telah diterapkan Ohim dalam akun Instagramnya.

Konsisten dalam buku Authentic Personal Branding (Rampersad, 2008) menyebutkan bahwa Anda harus konsisten dalam berperilaku. Seperti McDonald's yang menyajikan hamburgers dan cheeseburgers dengan produk yang selalu sama, lagi, lagi dan lagi.

Kekonsistenan yang diterapkan oleh Ohim dalam akun Instagramnya dapat dikatakan telah memenuhi kriteria bahwasanya terlihat pada 
akun@ibrhmrsyd, Ohim membentuk pola yang serupa, baik pada pekerjaannya, kesehariannya ataupun hubungannya. Konten yang disajikan sangatlah tertata akan satu konten dengan konten yang lainnya. Dalam mengunggah konten nya ke dalam akun@ibrhmrsyd, Ohim turut konsisten untuk tetap mengunggah kontenkonten fotonya yang tidak memiliki pandangan negatif.

McNally dan Speak (2011) dalam buku "Be Your Own Brand" turut mengemukakan bahwa dalam konsistensi, orang-orang menjadi yakin dalam suatu hubungan berdasarkan pada kekonsistenan perilaku yang mereka rasakan atau amati. Dalam kaitannya pada akun Instagram@ibrhmrsy, menurut pengamatan penulis, hal ini pun terlihat dari bagaimana setiap konten yang terdapat pada akunnya memiliki pola dilakukan sama dan berulang baik pada sisi modelling, talent, relationship sebagai seorang selebgram.

Hal tersebut dapat dikatakan konsisten karena penerapan yang terjadi dalam akun@ ibrhmrsyd telah mencerminkan kekonsistenan Ohim dalam mengatur feednya untuk membentuk benak khalayak. Dapat disimpulkan bahwa Ohim telah konsisten dengan konsep yang telah ditetapkannya.

Dalam membentuk personal branding (Rampersad, 2008) pada akun@ibrhmrsyd, Ohim mencondongkan akunnya dan dirinya ke dalam bidang fashion model. Hal ini dapat dilihat dari beragamnya konten foto dalam akun Instagram@ibrhmrsyd yang mengunggah foto saat show maupun sedang menjalani sesi photoshoot dengan mengedepankan sisi fashion model.

Seturut dengan kecondongan dirinya dalam bidang yang ditekuninya, perusahaan yang bekerjasama dengan dirinya pun turut memilih dirinya sebagai model maupun brand ambassador atau endorser dikarenakan kecocokan brand yang dimiliki oleh perusahaan seperti apa yang dituturkan oleh Ohim saat melakukan wawancara dengan penulis.

Lebih lanjut, penulis menyimpulkan bahwa Ohim memfokuskan dirinya ke dalam bagian fashion, dengan spesifikasi sebagai man model. Hal ini terlihat dalam akun-akun yang kembali mengunggah fotonya yang turut menekankan dirinya bahwa Instagram @ibrhmrsyd berkonsentrasi pada bidang fashion. Akun-akun yang mengunggah foto Ohim dalam akun@ ibrhmrsyd turut menegaskan bahwa dirinya memiliki kespesialisasian ke dalam bidang dan keterampilan yang ditekuninya, yaitu seorang model dan fashion, selaras dengan perusahaan yang mempekerjakan dirinya.

Authority yang dimaksud oleh Rampersad (2008) adalah untuk dilihat sebagai ahli yang diakui dalam bidang tertentu, sangat berbakat, sangat berpengalaman dan dianggap sebagai 
pemimpin yang efektif. Ohim dalam penerapan personal branding dirinya, turut diakui oleh klien-klien yang bekerja dengan dirinya, yaitu bidang fashion dengan penampilan casual. Pengalaman yang dimiliki pun cukup banyak dalam pengamatan penulis, terlihat dari konten yang dimilikinya dalam Instagram, bahwa dirinya telah mengikuti banyak fashion show serta photoshoot session yang semuanya turut diunggah ke dalam akun miliknya.

Menjadi seorang selebgram pun, Ohim turut selektif akan setiap tawaran pekerjaan yang ditawarkan pada dirinya, hal ini dilakukan untuk menguatkan dirinya bahwa Ohim dan akun@ibrhmrsyd adalah sebuah akun yang memang benar berkecimpung sebagai fashion street selebgram. Agar semakin memperkuat dirinya sebagai seorang pemimpin yang benar menjadi seorang selebgram berfokus pada bidang fashion.

Distinctiveness dalam buku Rampersad (2008) bermakna bedakan diri berdasarkan merek Anda. Personal brand Anda perlu diungkapkan dengan cara yang unik dan berbeda dari kompetisi dan kebutuhan guna menambah nilai bagi orang lain. Personal branding perlu didefinisikan dengan jelas agar orang lain dapat dengan cepat memahaminya.

Berdasarkan pengamatan dan penelitian yang penulis lakukan, Ohim menekankan dirinya untuk condong menjadi seorang selebgram pria yang berkompeten di bidang model, talent, serta relationship goals. Hal ini dirasa penulis kurang mendukung adanya kekhasan yang tercipta bagi Ohim dalam membentuk personal branding yang otentik pada sisi kekhasan. Untuk menjadi seorang selebgram pria, khusunya di Kota Bandung, penulis setuju dengan hal ini karena minimnya selebgram pria yang diketahui di Kota Bandung. Namun, untuk bidang yang ditekuni sebagai model dan talent serta relationship goals, hal tersebut kurang membentuk kekhasan tercipta pada Ohim dalam membangun personal branding yang dimilikinya.

Personal branding yang sedang dibangun haruslah terhubung dengan yang dianggap penting oleh target audiens (Rampersad, 2008). Pada akun Instagram@ibrhmrsyd, Ohim selalu mengunggah seluruh hasil kerjaannya, baik dalam kerjaannya, hubungannya, serta keseharian dirinya.

Hal tersebut menuai banyak respons dari khalayak yang dimiliki oleh Ohim dalam akunnya, seperti follow, likes, comment serta repost (pengunggahan kembali) yang dilakukan oleh akun lain. Dari percakapan yang dilakukan penulis dengan Ohim bahwa dengan konten yang Ohim unggah ke dalam akunnya, beberapa sutradara, fashion blogger, serta khalayak yang berkaitan dengan dunia fashion maupun khalayak biasa mulai mengikuti dirinya dalam akun Instagram serta konten dalam akun@ 
ibrhmrsyd diunggah kembali oleh beberapa akun. Hal ini dapat dilihat pada kolom tag dalam akun@ibrhmrsyd.

Dengan ini penulis menganalisa bahwa relevansi yang dibangun dengan menggunakan personal branding yang dibentuk oleh Ohim telah sesuai dengan followers atau khalayak yang dimilikinya. Karena khalayak menganggap bahwa konten yang dimiliki oleh Ohim berhubungan dengan khalayak serta dianggap penting.

Ditambahkan, menurut McNally dan Speak (2011), relevant adalah apa yang diwakili oleh merek tersebut berkaitan dengan apa yang dianggap penting oleh orang lain. Dengan adanya beberapa followers yang mengikuti akun Instagram @ibrhmrsyd dirasa bahwa khalayak tersebut berkecimpung di dunia yang selaras dengan yang Ohim tekuni. Penulis berpendapat bahwa khalayak menganggap akun@ibrhmrsyd termasuk ke dalam referensi mereka dan menganggap konten milik Ohim penting bagi mereka, sehingga mereka mulai mengikuti dan menjadi salah satu followers dalam akun@ibrhmrsyd.

Personal branding yang dibentuk harus disiarkan berkali-kali, terus menerus, konsisten dan berulang kali hingga tertanam di benak audiens (Rampersad, 2008). Dalam hal ini, menurut pengamatan penulis akun Instagram @ ibrhmrsyd telah memenuhi kriteria visibilitas. Hal ini terlihat dari konten Instagram @ ibrhmrsyd yang selalu terpolakan dan selalu mengikuti kekonsistenan yang telah ditetapkan

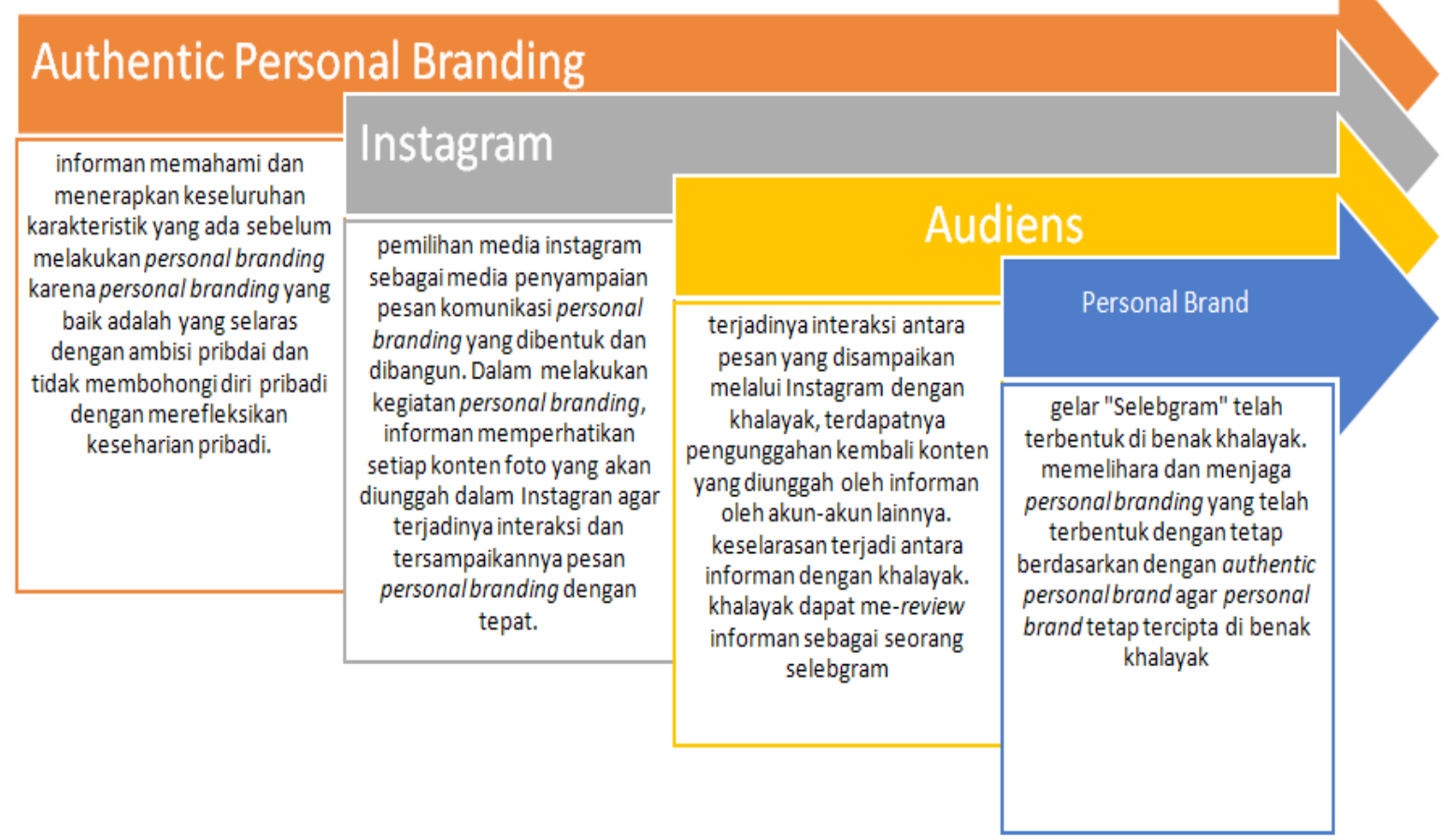

Sumber: Hasil Penelitian, 2016

\section{Gambar 1 Pembentukan Personal Branding Ohim}




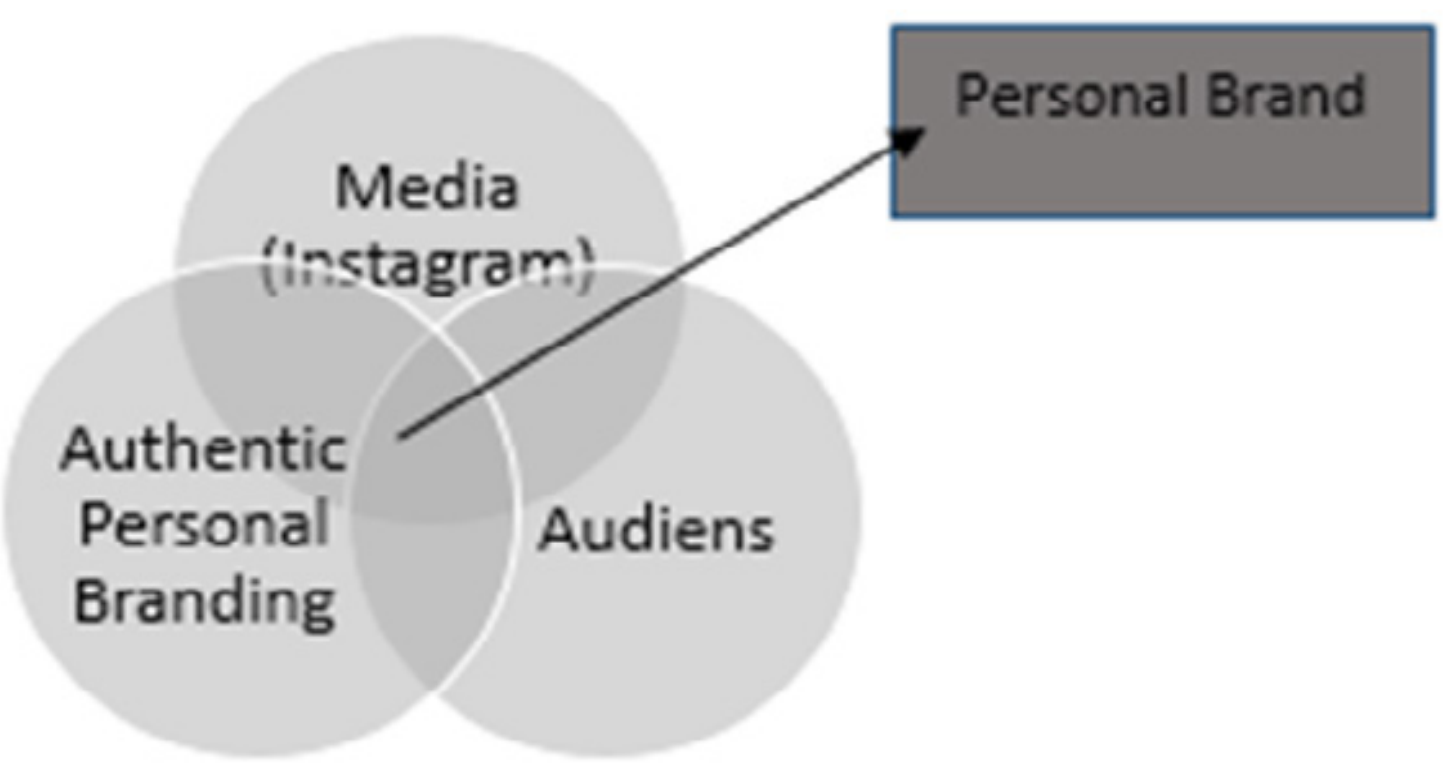

Sumber: Hasil Penelitian, 2016

Gambar 2 Strategi Personal Branding

sebelumnya. Dalam setiap kegiatan yang dijalani oleh Ohim pun, tidak lupa dirinya menggunggah konten foto kegiatan dirinya yang sedang maupun yang telah dijalaninya.

Secara terus-menerus dan berulang kali dirinya menggunggah konten foto yang bertemakan fashion untuk mengatasnamakan dirinya adalah seorang selebgram yang berkecondongan di dunia fashion. Sehingga dampak dari visibilitas yang dilakukan Ohim dalam akunnya pun dapat juga dilihat dari banyaknya akun yang kembali menggunggah fotonya serta feed miliknya dalam akun Instagram yang rapih akan penampilan dirinya.

Membentuk dan membangun personal branding yang otentik membutuhkan suatu kegigihan dalam upayanya. Personal branding menurut Peter Montoya adalah sebuah proses yang melibatkan kemampuan, personalitas, dan karakter unik seseorang dan mengemas mereka ke dalam sebuah identitas yang kuat yang mengangkat seseorang yang bersangkutan ke atas lautan muka dan kompetitor (Tobing. 2016).

Merek besar seperti Tiger Woods, Oprah Winfrey telah melewati bertahun-tahun untuk menjadi ikon. Semua itu dibutuhkan dedikasi, pengorbanan, keberanian, perencanaan dan kesabaran untuk bertahan (Rampersad, 2008).

Dari hasil penelitian, kegigihan Ohim dalam membentuk dan membangun personal branding yang dimilikinya sebagai seorang selebgram dimulai kurang-lebih satu tahun yang lalu. Dalam membangun personal branding, Ohim tetap teguh untuk menjadi diri sendiri apa adanya layaknya keseharian dirinya.

Pada hal mengatur konten yang akan diunggah ke dalam akun Instagramnya pun 
Ohim selalu teguh untuk memperhatikan bahwa konten yang diungah harus memiliki value yang baik, baik untuk dirinya pribadi maupun untuk khalayak yang dimilikinya. Menurut DeMers (dalam Kurniullah, 2017) terdapat tujuh karakteristik yang dapat mengukur suksesnya suatu brand, yaitu audience knowledge, uniqueness, passion, consistency, competitiveness, exposure, dan leadership.

Perencanaan konten selalu dilakukan Ohim untuk terus dapat berinovasi akan isi dari Instagram yang dimilikinya dengan memperbanyak konten yang akan diunggah ke dalam Instagram dan tidak memiliki kesamaan jenis pada setiap kontennya. Hasil dari kerja kerasnya dalam membentuk dan membangun personal branding dirinya adalah beragamnya media-media yang mengakui bahwa dirinya adalah seorang selebgram, tanpa adanya pengakuan pribadi bahwa Ohim adalah seorang selebgram.

Orang-orang berbisnis dengan orang yang mereka sukai (Rampersad, 2008). Personal brand Anda akan menghasilkan hasil yang baik dan bertahan lebih lama jika dirasakan itu adalah hal yang positif. Anda harus berkaitan dengan hal yang diakui positif dan bermanfaat.

Pandangan positif yang datang dari khalayak tersebut tidak datang dengan sendirinya, tetapi berasal dari nilai-nilai yang sudah ditanamkan dan diaplikasikan oleh pelaku personal branding. Keprofesionalan Ohim dalam bekerja sebagai seorang selebgram, maupun ditunjuk sebagai brand ambassador untuk mewakili produk-produk kliennya serta menjadi seorang endorser dirasa penulis cukup memenuhi karakteristik good will dalam membentuk personal branding yang otentik. Hal ini dapat dilihat dari terjadinya kerja sama jangka panjang pada ohim maupun perusahaan yang bekerjasama dengan dirinya.

Karakteristik terakhir dalam membentuk personal branding yang otentik adalah performance (Rampersad, 2008). Dalam menjaga eksistensi Ohim menjadi seorang selebgram, Ohim akan selalu menjaga interaksi yang terjadi dalam akunnya @ibrhmrsyd dengan cara tetap mengunggah konten-konten pada akunnya. Hal ini dilakukan untuk tetap menjangkau khalayak yang dimilikinya agar akun@ibrhmrsyd terlihat sebagai sebuah akun yang selalu beraktivitas.

Selanjutnya, untuk menjaga keseluruhan personal branding yang telah dibentuk, kunci dari segalanya adalah untuk tetap menjadi diri sendiri, yang dimaksud adalah tidak merubah ataupun lari dari alur yang telah ditetapkan oleh Ohim. Tetap menjalankan setiap unsur karakteristik yang ada guna menyempurnakan personal branding yang dibentuk.

Ditambahkan, Ohim tetap melakukan pengecekan terhadap akun Instagram yang 
dimilikinya, setiap unsur yang terdapat di Instagramnya selalu diperhatikan. Interaksi kepada khalayak pun juga turut dipertimbangkan seperti baik-buruknya suatu comment yang masuk pada akunnya selalu dibalas dan disaring agar mendukung personal branding yang dibentuk dan dibangunnya pada akun@ ibrhmrsyd.

Berdasarkan analisa penulis terhadap data yang telah didapat melalui wawancara dengan informan serta pengamatan yang dilakukan dalam akun@ibrhmrsyd, dapat disimpulkan pada gambar 1 yaitu strategi pembentukan personal branding melalui media sosial (Instagram). Penulis berusaha untuk membentuk proses personal branding yang terjadi dan menggambarkan strategi personal branding ke dalam grafik pada gambar 1, bahwa ketiga unsur authentic personal branding, Instagram sebagai media serta audiens membentuk adanya personal brand yang baik serta kuat. Seperti yang dapat digambarkan pada bagan gambar 2 .

Authentic personal branding: Penerapan kesebelas karakteristik dengan berdasarkan ambisi pribadi yang selaras dengan keseharian pribadi, tidak membohongi pribadi dalam menciptakan merek agar terciptanya merek pribadi yang baik dan bertahan lama. Media (Instagram): Instagram sebagai alat serta media penyampaian pesan personal brand yang dibentuk dan dibangun dengan memperhatikan fitur-fitur yang diberikan, sehingga dapat membuatnya unik dan memberikan inovasi.

Dengan adanya Instagram sebagai media komunikasi, menurut Kartikawangi (2013), suatu produk maupun jasa dapat dikomunikasikan melalui email, website, dan media sosial lainnya. Audiens: Instagram sebagai media memiliki audiens sehingga personal brand disampaikan kepada audiens, feedback yang diperoleh berupa like, comment, serta pengunggahan kembali (repost/regram). Interaksi terjadi antara pemilik personal brand dan audiens. Personal brand: personal brand telah terbenak pada audiens dan telah terbentuk, pribadi pemilik personal brand perlu melakukan maintenance untuk menjaga keberlangsungan personal brand yg dibentuk agar selalu baik dan bertahan lama.

\section{SIMPULAN}

Strategi personal branding selebgram non selebriti pada Ohim dengan akun Instagram @ ibrhmrsyd secara keseluruhan bahwa Ohim hadir dengan akun Instagram @ibrhmrsyd sesuai dengan kesebelas karakteristik personal branding (authenticity, integrity, consistency, specialization, authority, distinctiveness, relevant, visibility, persistence, goodwill, performance). Authenticity, sebagai selebgram berprestasi dan seorang yang simple. Integrity, memiliki konten yang teratur dan selalu positif, 
yaitu memilah dan melakukan penyaringan pada konten. Specialization, bidang fashion model men. Authority, pengakuan dari klien yang bekerja sama dengan diri Ohim serta pengalaman yang dimilikinya. Relevant, yaitu banyaknya akun yang mengikutinya maupun yang memberikan respons serta pengunggahan kembali konten Ohim dalam Instagram. Visibility dan konsistensi terlihat dari seringnya Ohim mengunggah kontennya serta selalu memiliki penggambaran yang serupa dan tertata sehingga semakin memperjelas dirinya pada khalayak. Terakhir, perencanaan konten, keteguhan Ohim dalam konten unggahannya serta pandangan positif yang diraihnya menjadi poin dalam persistence, goodwill serta menjalin interaksi dengan tetap berdasarkan kesepuluh karakteristik sebelumnya sebagai kunci dalam performance.

Namun, Ohim tidak memiliki visi dalam menjadi seorang selebgram pada sisi authenticity dan distinctiveness, Ohim kurang memiliki kedalaman dalam menciptakan kekhasan dirinya sebagai pribadi yang dibentuknya. Adapun personal branding yang telah dibentuk kemudian disatukan dengan media yang dimiliki, yaitu Instagram serta terdapatnya audiens yang menerima pesan personal branding yang ingin disampaikan. Maka terciptalah personal brand di benak khalayak.

Penelitian selanjutnya dapat dilakukan dengan menggunakan objek yang sama dengan subjek maupun platform yang berbeda agar lebih menggali penelitian tentang personal branding. Selain itu dapat pula dilakukan penelitian dengan menyempurnakan penggunaan konsep yang ada pada penelitian ini, seperti authenticity dan distinctiveness.

\section{DAFTAR PUSTAKA}

Kartikawangi, D. (2013). Evaluasi strategi dan implementasi 3600 communications di indonesia. Jurnal Interact. Vol. 2 No. 1, 18-31.

Kurniullah, A. Z. (2017). Strategy viral marketing pt. musim multi media untuk meningkatkan traffic social media fansfage dan brand engagement. Jurnal Visi Komunikasi. Vol. 14 No. 2, 169-178.

Mc Nally \& Speak. (2011). Be your own brand: achieve more of what you want by being more of who you are. San Fransisco: BerretKoehler Publisher.

Moleong, L. J. (2012). Metodologi penelitian kualitatif. Bandung: Remaja Rosdakarya.

Nugraha, A. R. (2017). Branding kota bandung di era smartcity. Jurnal Ilmu Komunikasi, Vol. 8 No. 1, 1-16.

Pattipeilohy, E. M. (2015). Citra diri dan popularitas artis. Jurnal Kajian Komunikasi. Vol. 3 No. 1, 22-32.

Rakhmat, J. (2009). Metode penelitian komunikasi dilengkapi contoh analisis statistik. Bandung: Remaja Rosdakarya.

Rampersad, H. K. (2008). Authentic personal branding. Jakarta: PPM Publishing.

Setianti, Y. (2016). Pemanfaatan media sosial dalam implementasi model komunikasi kesehatan reproduksi remaja. Komunikatif: 
Jurnal Ilmiah Komunikasi. Vol. 5 No.1, $1-24$.

Tobing, C. R. L. (2016). Personal branding putri danizar sebagai disc jockey muda indonesia. Communication. Vol. 7 No. 2, 65-83. 